\title{
Article
}

\section{The Prevalence and Overlaps of Temporomandibular Disorders in Patients with Myofascial Pain with Referral-A Pilot Study}

\author{
Joanna Kuć ${ }^{1, *(\mathbb{C},}$, Krzysztof Dariusz Szarejko ${ }^{2}$ and Maria Gołębiewska ${ }^{3}$ \\ 1 Department of Prosthodontics, Medical University of Bialystok, 24A M. Sklodowskiej-Curie St., \\ 15-276 Bialystok, Poland \\ 2 Private Health Care, Physical Therapy and Rehabilitation, 79 Warsaw St., 15-201 Bialystok, Poland; \\ biuro@rehabilitacja-lecznicza.pl \\ 3 Department of Dental Techniques, Medical University of Bialystok, 13 Washington St., \\ 15-269 Bialystok, Poland; maria.golebiewska5@gmail.com \\ * Correspondence: joanna.kuc@umb.edu.pl
}

Citation: Kuć, J.; Szarejko, K.D.; Gołębiewska, M. The Prevalence and Overlaps of Temporomandibular Disorders in Patients with Myofascial Pain with Referral-A Pilot Study. Int J. Environ. Res. Public Health 2021, 18, 9842. https://doi.org/10.3390/ ijerph18189842

Academic Editors: Fawad Javed and Takaaki Tomofuji

Received: 2 August 2021

Accepted: 14 September 2021

Published: 18 September 2021

Publisher's Note: MDPI stays neutral with regard to jurisdictional claims in published maps and institutional affiliations.

Copyright: (c) 2021 by the authors. Licensee MDPI, Basel, Switzerland. This article is an open access article distributed under the terms and conditions of the Creative Commons Attribution (CC BY) license (https:// creativecommons.org/licenses/by/ $4.0 /)$

\begin{abstract}
The aim of the study was to evaluate the temporomandibular joint, the prevalence of single and multiple diagnosis and potential sided domination of temporomandibular dysfunction in patients with temporomandibular disorder-myofascial pain with referral. The study group enrolled 50 people -37 females and 13 males between 18 and 25 years old with an average age of $23.36 \pm 2.14$. The patients underwent joint vibration analysis. Sixty seven percent of all examined tem-poromandibular joints were classified as group I according to Mark Piper's classification. Class IIIA appeared in $17 \%$ of joints. Eight percent of temporomandibular joints were classified as class IVA. There were no statistically significant differences in the prevalence of temporomandibular disorder with respect to gender $(p=0.838639)$. The relatively high prevalence of multiple diagnoses proved the overlapping nature of muscle and intraarticular disorders. Twenty eight percent of the subjects suffered from a combination of myofascial pain with referral and bilateral temporoman-dibular dysfunction. In $62 \%$ of the patients a lack of intraarticular disorders was reported. The suggestion that there exists sided domination in the occurrence of temporomandibular disorders has not been confirmed. Due to the small sample size, such differences cannot be excluded. Fur-ther research is needed.
\end{abstract}

Keywords: joint vibration analysis; myofascial pain with referral; temporomandibular disorder; temporomandibular joint

\section{Introduction}

Temporomandibular disorders (TMDs) affect approximately $5 \%$ to $12 \%$ of the adult population [1]. In children, the prevalence ranges from $9.8 \%$ to $80 \%$, and the variation in frequency depends on the adopted diagnostic criteria [2]. About $60-70 \%$ of the human population has at least one TMD symptom in their lifetime but only $5 \%$ of cases undertake the treatment [3]. With regard to gender, the literature reveals countless studies which indicating the occurrence of female predominance [4]. Women are twice as likely as men to suffer from TMD [5].

TMDs represents a group of musculoskeletal/neuromuscular conditions that may affect masticatory muscles, the temporomandibular joint (TMJ) and its associated structures [6,7]. The main symptoms and signs of TMD include masticatory pain, headaches, limited mandibular motion and its deviation pattern, TMJ noises, subluxation or/and jaw locked, jaw functional limitations, neck pain and poor sleep quality [8-12]. The etiology is multifactorial in nature and involves the overlapping of biological, behavioral, environmental, social, emotional and cognitive aspects $[13,14]$. These components can be considered as initiating, predisposing or perpetuating factors. The most common reasons concern direct and indirect trauma, repetitive microtrauma, systemic and local factors, postural and 
parafunctional habits, genetic determination as well as psychosocial findings relating to depression and anxiety $[2,6,8,13,15-19]$. The role of occlusion still remains unclear [20-25]. Causative factors can act independently, mutually and synergistically. In most cases it is usually impossible to identify a single leading factor.

TMDs reflects a group of comorbid conditions and clinical issues in which the incidence of muscular dysfunction tend to be more common than those which are intra-capsular joint-related [26-28]. Myofascial disturbances arise from tension, fatigue or spasm of the masticatory muscles whereas intra-articular disorders derive from mechanical or inflammatory damage to the joint itself. Muscle dysfunction seems to be the primary cause of TMD development [29].

Myofascial pain is one of the most common disorders of the temporomandibular joints, which represents a subtype of myalgia according to the first axis of the Diagnostic Criteria for Temporomandibular Disorders (DC/TMD) [1]. Some reports indicate that the overall prevalence of TMD myofascial pain amounts to $45.3 \%$ [30]. Other literature estimates that even more than $50 \%$ of temporomandibular disorders reflect myofascial pain [31]. As a temporomandibular disorder myofascial pain with referral is manifested through pain of muscle origin including pain spreading beyond the boundary of the masticatory muscles [32]. The limitation of mandibular motion occurs secondarily to pain [32]. Clinical pattern is always related to trigger points located in the head and neck region. As a consequence, autonomic, motor and sensory reactions appear, including local and transferred pain [30,33]. It should be noted that myofascial pain is the most common cause of orofacial pain, which modifies quality of life and biopsychosocial wellbeing [32,34,35]. Resultantly, depression, anxiety and somatic disorders appear.

Currently, for better diagnosis and more efficient treatment of TMDs, instrumental analysis including electromyography, electrovibratography, electrosonography, electrognathography, thermography, electrokinetic and axiographic measurements, as well as the occlusal analysis system should be considered [27]. These biometric approaches enable quantitative assessment of the temporomandibular joint and bridge the gap between clinical procedures and TMJ Imaging [36].

The aim of this pilot study was to evaluate the temporomandibular joint, the prevalence of single and multiple diagnosis and potential sided domination of temporomandibular dysfunction in patients with temporomandibular disorder-myofascial pain with referral.

\section{Materials and Methods}

\subsection{Ethical Issues}

The study was approved by the Ethics Committee of the Medical University of Bialystok, Poland (permission number: R-I-002/322/2016). The research was carried out in accordance with the principles of the Declaration of Helsinki of the World Medical Association and the Guidelines for Good Clinical Practice. Participation in the study was voluntary. All the subjects obtained comprehensive information about the nature, scope of clinical activities and the course of the proceedings. At every stage, patients had the right to refuse to participate in the research without consequences. Participation in the study had been preceded by a written consent by every subject.

\subsection{Subjects and the Size of the Sample}

The study group enrolled 50 people -37 females and 13 males. All patients had complete natural dentition. They were referred to the Department of Prosthodontics at the Medical University of Bialystok, Poland. The study recruited people between 18 and 25 years old with an average age of $23.36 \pm 2.14$ years. All subjects underwent a clinical examination according to the Diagnostic Criteria for Temporomandibular Disorders (DC/TMD) (Axes I and II) and were identified with myofascial pain with referral (Axis I of DC/TMD) [37]. Qualification testing was conducted by a dentist who is also a physiotherapist (J.K.). 


\subsubsection{Inclusion Criteria}

- Myofascial pain with referral (Axis I of DC/TMD)

- Pain within the craniofacial and/or craniomandibular region (VAS, Visual Analogue Scale $\geq 8$ points).

- Complete natural dentition (Class I of Angle's Molar Classification, canine position).

- No history of orthodontic therapy or lack of retention status over 3 years after the treatment completion.

\subsubsection{Exclusion Criteria}

- Trauma within the craniofacial and/or craniomandibular area.

- Surgical treatment within the craniofacial and/or craniomandibular region.

- Dental therapy supported by an occlusal splint.

- Prosthetic treatment and/or physiotherapy within the craniofacial and/or craniomandibular region in the medical history.

- Cases with possible health concerns affecting the function of the masticatory muscles.

- Metabolic diseases.

- Drugs.

The sample was described in detail in previous publications $[5,33,38,39]$.

\subsection{General Description of the Method}

All patients underwent a thorough examination. The procedure followed:

- functional assessment of the masticatory system with respect to the Diagnostic Criteria for Temporomandibular Disorders (DC/TMD) [37]—axes I and II;

- Joint Vibration Analysis (JVA, BioResearch, Inc., Milwaukee, WI, USA);

- $\quad$ statistical analysis using the Statistica 13.1 (Statsoft Inc., Cracow, Poland), PQStat Software v. 1.8.2.182 (PQStat Software, Poznan, Poland) and G Power v. 3.1.9.4 (Germany).

\subsection{General Description of the Joint Vibrations Analysis (BioJVA)}

The BioJVA device enables bilateral registration of temporomandibular vibrations (Figure 1). Two preauricular sensors use the piezoelectric phenomenon. In order to suppress interference from the surrounding environment, the detectors are covered with a silicone mass ensuring plane contact with the skin of the person under examination. Temporomandibular joint vibrations generate pressure, which, by influencing the piezo crystals, releases an acoustic wave that is transferred directly onto the computer screen in real time and is expressed in graphs as dependence of vibration amplitude and time. The software (Biopak, BioResearch, Inc., Milwaukee, WI, USA) paired with the device allows for the specification each reported vibration.

The requirement for a reliable and correct single registration is repeatable translation of both condyles to their full extent-provided by a repeatable pre-declared range of the mouth opening - and the subsequent subtle intermaxillary occlusal contact during the clenching of both dental arches, coupled with the action of the metronome. Full condylar movements reveal limitations in the range of mandibular motion, deviations, deflections and potential temporomandibular vibrations. The subtle intermaxillary occlusal contacts facilitate verification of the maximum mandibular range of motion included in the single registration.

The range of motion (ROM) is specified as the distance between the incisal edges of the upper and lower central incisors in the position of maximum mouth opening enlarged by the overbite. Lateral deflection (LD) reflects the discrepancy between the interincisal point of the lower central incisors and the mid-sagittal plane in the position of the maximum mouth opening. Both measurements (ROM and LD) are expressed in millimeters and should be initially entered into the software at the beginning of the registrations [36]. 


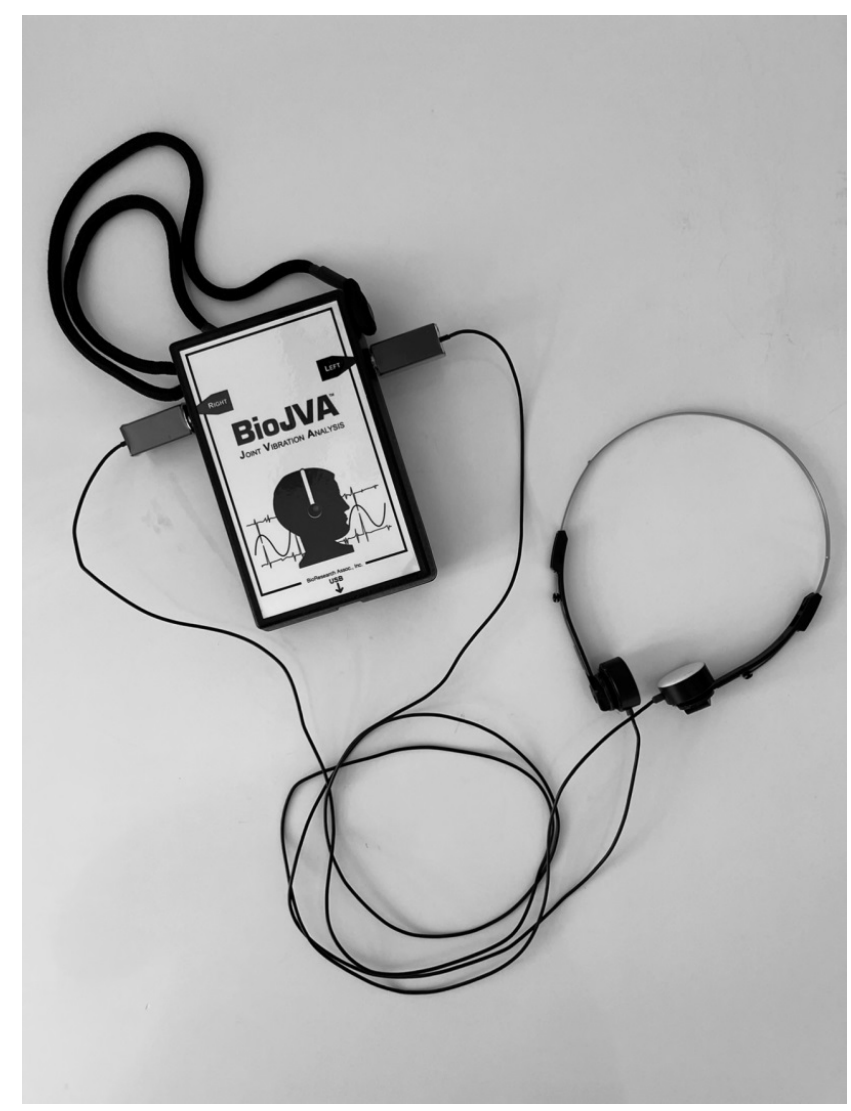

Figure 1. BioJVA Device (BioResearch, Inc., Milwaukee, WI, USA).

The BioJVA allows for the classification of the condition of the individual temporomandibular joint in relation to Mark Piper's classification, which was defined with respect to the results of Magnetic Resonance Imaging (MRI) and reflects modification of a classification scheme by Tasaki and Westesson [40,41]. The key stage of categorization is the analysis of the course of the vibration wave, taking into account the reference notation of the waveform (JVA Flow Chart) [36].

\subsection{Joint Vibration Recording Procedure (BioJVA Procedure)}

JVA registrations were performed in the morning, under the conditions of suggestive relaxation with no background noise, no side conversations and with no third parties accompanying the patient. A lack of visual, auditory and multisensory distractors (bright monitor light, radio and smartphones, respectively) was adhered to. The clinical procedure was performed by an experienced dentist specialized in prosthodontics and physiotherapist in one person (the author J.K).

Two accelerometers mounted to the arch running over the cranial vault were positioned in the preauricular area directly over TMJ's (Figure 2). Patients were asked to open the mouth as wide as possible, then clench both dental arches together to a subtle occlusal contact and repeat these activities several times (usually six or more complete cycles of the opening and closing of the mouth) following the metronome to control the velocity of the motion and the time of registration (10 s). One-minute breaks between consecutive registrations were respected. In order to reduce impedance, in each case the facial skin and accelerometers were rinsed with $2 \%$ salicylic alcohol.

During registration the patients remained upright and sitting in the initial default position of the adjustable office stool without lumbar support. Feet were positioned symmetrically on the floor, one foot apart from each other, hands rested on the thighs. The patients looked straight ahead. Prior to registration, the patients were oriented according to the Upright Posture Position of the Mandible (UPPM position) [42]. 


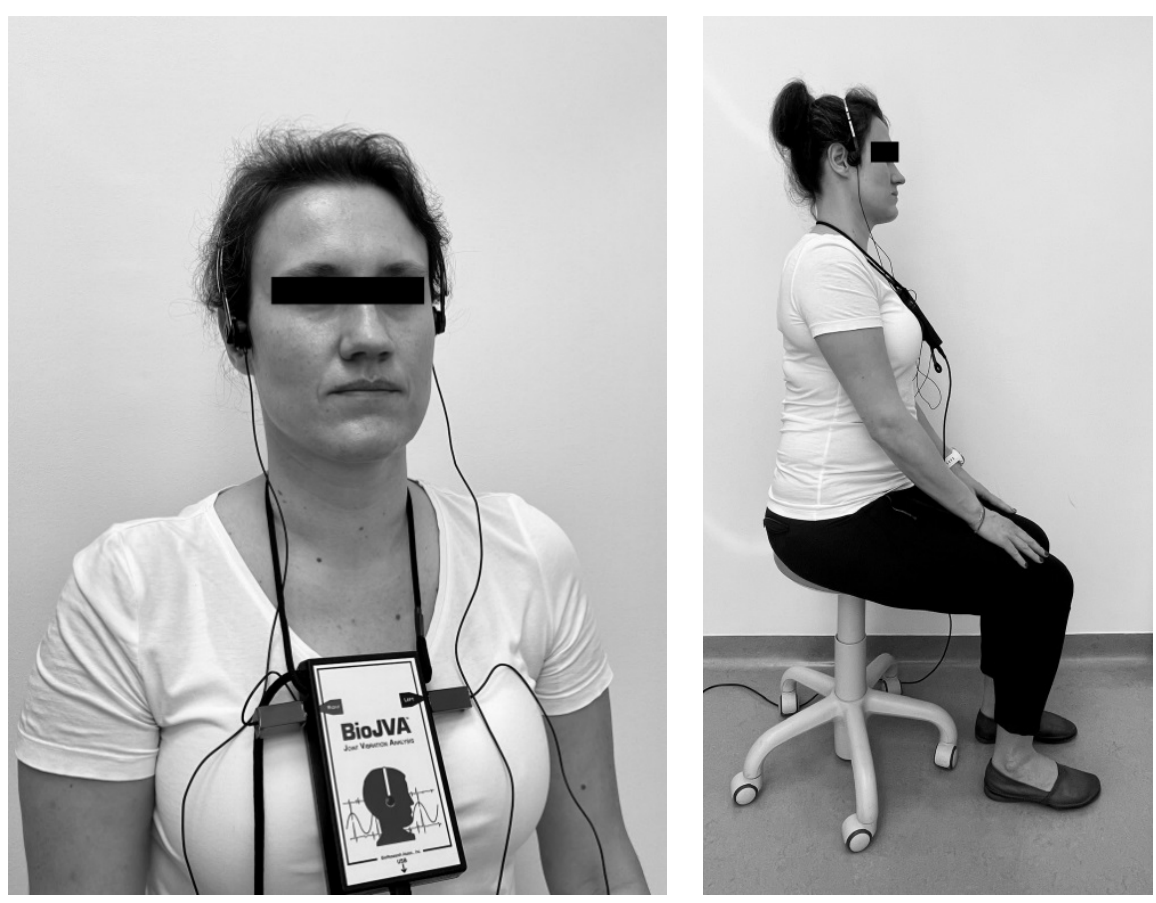

Figure 2. Position of the patient during the joint vibration recording procedure.

\subsection{Statistical Analysis}

Statistical analysis was performed using Statistica 13.1 (Statsoft Inc., Cracow, Poland), PQStat Software v. 1.8.2.182 (PQStat Software, Poznań, Poland) and G Power v. 3.1.9.4 (Germany). The arithmetic mean and median as well as measures of differentiation including standard deviation were calculated. To compare categorical variables Pearson's chi-squared test of independence for a $2 \times 2$ contingency table was applied. A one-sided Fisher's exact test was used in the case of small sample size when the expected number of frequencies was below 5 . The Wilcoxon test was used to assess significant differences in the groups divided according to the side of the joint (right/left).

Statistical significance was established at $p<0.05$. For the one-sided Fisher's exact test and Wilcoxon test, a post-hoc power analysis was conducted. The statistical power $(1-\beta)$ was calculated as the function of the population effect size, sample size $(n)$ and $\alpha$. We additionally assessed the sample size required for the revealing of a statistically significant difference with respect to gender and to the side of the joint (right/left) at the 0.05 level with a probability of $0.8(80 \%)$.

\section{Results}

Sixty seven percent $(n=67)$ of all examined temporomandibular joints were classified as group I, of which $33 \%(n=33)$ were on the right side, and $34 \%(n=34)$ were on the left side (Table 1). Class IIIA was showed in $17 \%(n=17)$ joints and class IIIB in only $1 \%(n=1)$. Eight percent $(n=8)$ of joints were classified as class IVA, 3\% $(n=3)$ demonstrated class IVB. Two percent $(n=2)$ of joints were recorded in class VA and VB (Table 1). Sixty-eight percent $(n=50)$ of joints in females belonged to group I. In the case of males, the prevalence of this class was $65 \%(n=17)$ (Table 1). Class IIIB, IVB and VB were not found in the group of males (Table 1). There were no statistically significant differences in the prevalence of temporomandibular disorder with respect to gender $\left(\mathrm{Chi}^{2}=0.041467 ; p=0.838639\right)$ (Table 1). The test's power to detect the specified effect was on the low level (Fisher's Exact Unilateral Test: $p=0.510052 ;(1-\beta)=0.0570152)$ (Table 1). No sided domination in the occurrence of temporomandibular dysfunction was found (Table 1). 


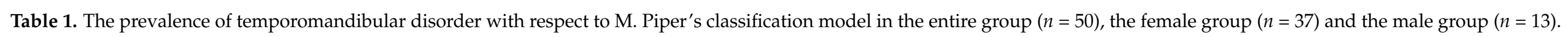

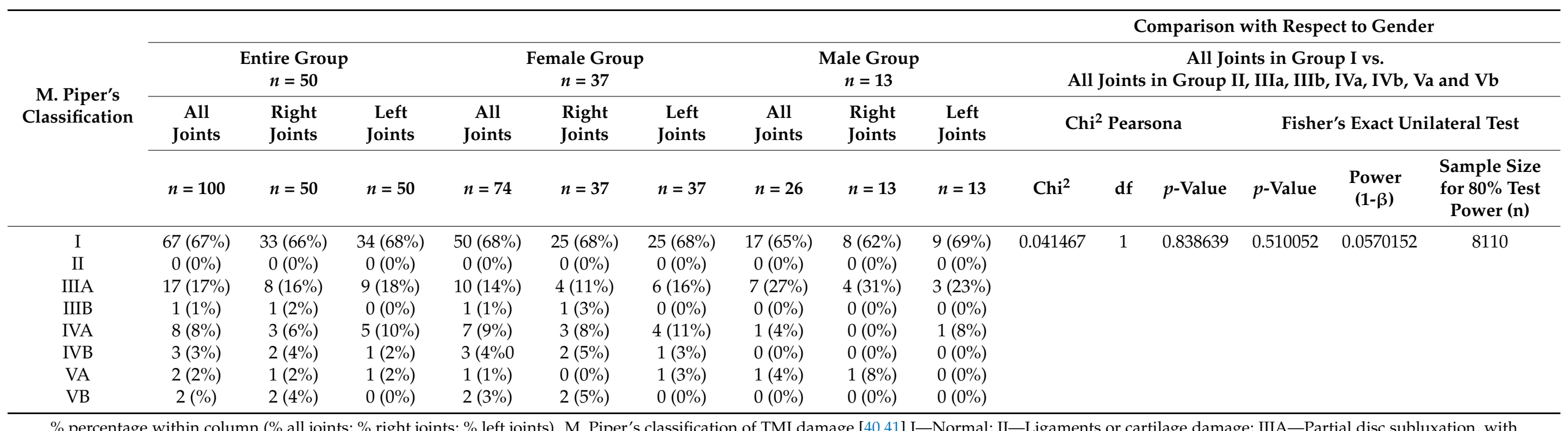

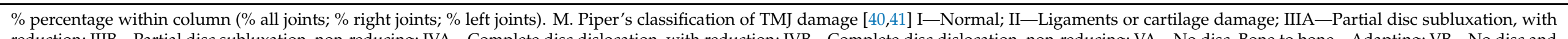

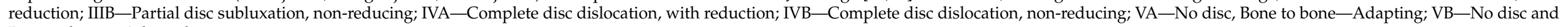
Bone to bone-Adapted. 
Sixty-two percent $(n=31)$ of the patients demonstrated a normal condition for both TMJs (Table 2). The bilateral stage 3A was reported in 10\% of people. Four percent $(n=2)$ of the subjects showed the bilateral stage 4A. Two percent of patients suffered from the condition $4 \mathrm{~B}$. The remaining $22 \%$ of the patients suffered from different combinations of diagnoses for both temporomandibular joints (Table 2). There were no statistically significant differences in the prevalence of combined diagnosis with respect to gender. The test's power to detect the specified effect was on a low level (Fisher's Exact Unilateral Test: $p=0.60975 ;(1-\beta)=0.0277777)$ (Table 2). No sided domination in the occurrence of temporomandibular dysfunction was found (Table 2).

In the entire study group, the mean of the total vibration energy (Total Integral) on the right side was $29.08 \mathrm{KPaHz}$ and on the left was $31.88 \mathrm{KPaHz}$ (Table 3). The median values were at the level of 7.20 and $7.85 \mathrm{KPaHz}$, respectively. In the case of vibration $<300 \mathrm{~Hz}$, the results in the case of both joints were comparable and amounted to $25.05 \mathrm{KPaHz}$. There were no statistically significant differences of the Total Integral and Integral $<300 \mathrm{~Hz}$ between the right and left temporomandibular joints $(p>0.05)$ (Table 3$)$. The total energy of vibrations for frequencies $>300 \mathrm{~Hz}$ were $4.04 \mathrm{KPaHz}$ on the right and $6.81 \mathrm{KPaHz}$ on the left side.

The mean peak frequency (Peak FreQ) was $48.74 \mathrm{~Hz}$ within the right TMJ and $71.52 \mathrm{~Hz}$ in the left one. The vibration frequency (Med. FreQ) amounted to $111.88 \mathrm{~Hz}$ on the right, while on the left it was $148.14 \mathrm{~Hz}$ (Table 3). Statistically significant differences of the Integral $>300 \mathrm{~Hz},>300 /<300 \mathrm{~Hz}$ Ratio, Peak FreQ and Med. FreQ were noted between the right and left temporomandibular joints $(p<0.05)$. Higher values of these parameters were reported on the left side (Table 3). The maximum range of mouth opening within the entire study group was $49.90 \mathrm{~mm}$ (Table 3).

Within the female group, the mean total energy of vibrations on the right side was $32.89 \mathrm{KPaHz}$ and on the left was $31.86 \mathrm{KPaHz}$ (Table 4). The median values were 8.00 and $8.20 \mathrm{KPaHz}$, respectively. In the case of vibrations $<300 \mathrm{KPaHz}$, the results were at the level of $28.87 \mathrm{KPaHz}$ on the right side and $25.14 \mathrm{KPaHz}$ on the left side. The total vibration energy for frequencies $>300 \mathrm{~Hz}$ on the right amounted to $4.03 \mathrm{KPaHz}$ and on the left was $6.73 \mathrm{KPaHz}$.

The mean peak frequency was $43.68 \mathrm{~Hz}$ on the right and $75.11 \mathrm{~Hz}$ on the left. The vibration frequency (Med. FreQ) amounted to $114.05 \mathrm{~Hz}$ within the right joint and on the left was $149.11 \mathrm{~Hz}$. Statistically significant differences of the $>300 /<300 \mathrm{~Hz}$ Ratio, Peak Frequency and Median Frequency were noted between the right and left temporomandibular joints $(p<0.05)$. Higher values of these parameters were reported on the left side (Table 4). The maximum range of mouth opening was $48.95 \mathrm{~mm}$ (Table 4).

In the case of males, the mean total vibration energy on the right was $18.24 \mathrm{KPaHz}$ and on the left was $31.94 \mathrm{KPaHz}$. The median values amounted to the level of $6.40 \mathrm{KPaHz}$ and $6.90 \mathrm{KPaHz}$, respectively. In the case of vibrations $<300 \mathrm{~Hz}$, the results reached $14.16 \mathrm{KPaHz}$ on the right side and $24.82 \mathrm{KPaHz}$ on the left side. The total energy of vibrations for frequencies $>300 \mathrm{~Hz}$ on the right side was $4.07 \mathrm{KpaHz}$ and on the left was 7.06 KPaHz.

The mean peak frequency was $63.15 \mathrm{~Hz}$ on the right and $61.31 \mathrm{~Hz}$ on the left. The vibration frequency (Med. FreQ) amounted to $105.69 \mathrm{~Hz}$ on the right side, while on the left it was $145.38 \mathrm{~Hz}$. Statistically significant differences between right and left temporomandibular joints were noted only in the case of the Median Frequency $(p<0.05)$. A higher value for this parameter was reported on the left side (Table 5). The maximum range of mouth opening for the male group was $52.62 \mathrm{~mm}$ (Table 5). 


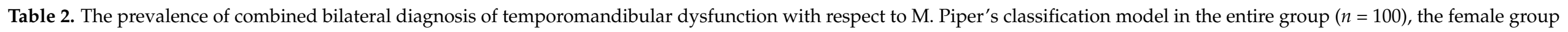
$(n=74)$ and the male group $(n=26)$.

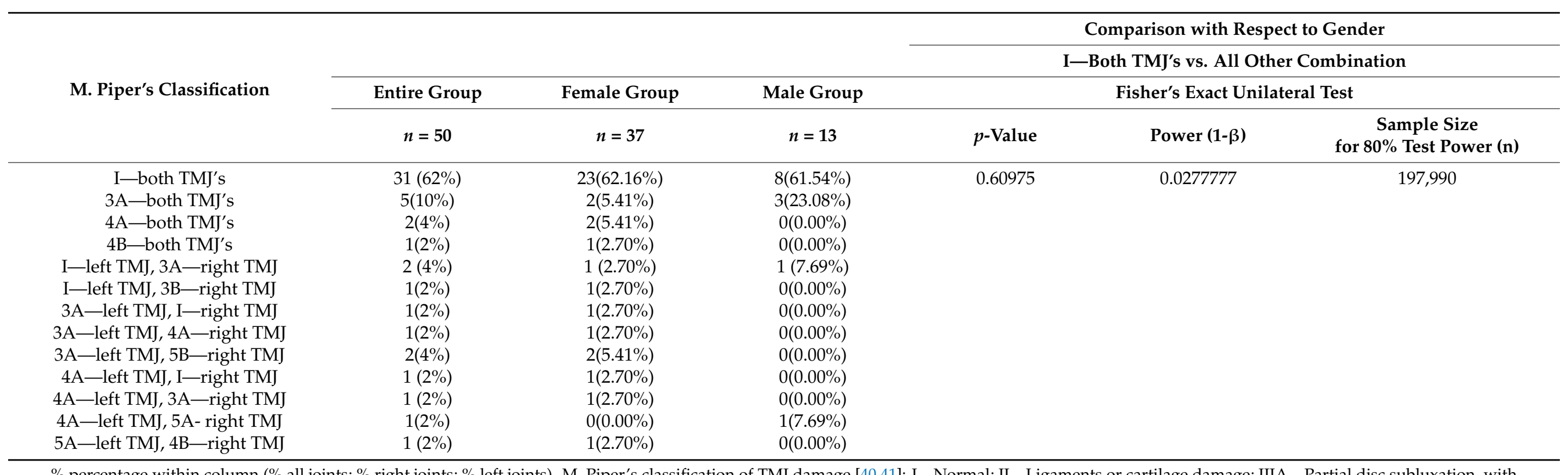

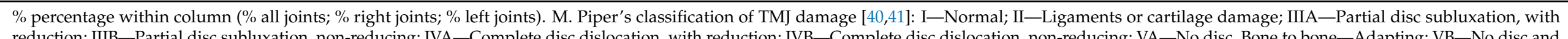
Bone to bone-Adapted. 


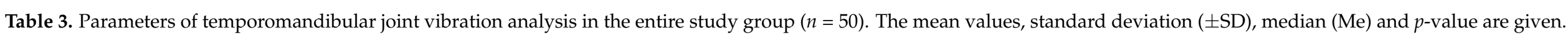

\begin{tabular}{|c|c|c|c|c|c|c|c|c|c|c|c|c|}
\hline \multirow{3}{*}{$\begin{array}{l}\text { Parameters of Joint } \\
\text { Vibration Analysis }\end{array}$} & \multirow{2}{*}{\multicolumn{3}{|c|}{$\begin{array}{l}\text { All Joints in the Entire Study } \\
\text { Group } n=100\end{array}$}} & \multirow{2}{*}{\multicolumn{3}{|c|}{$\begin{array}{l}\text { All Right Joints in the Entire Study } \\
\text { Group } n=50\end{array}$}} & \multirow{2}{*}{\multicolumn{3}{|c|}{$\begin{array}{l}\text { All Left Joints in the Entire Study } \\
\text { Group } n=50\end{array}$}} & \multirow{2}{*}{\multicolumn{3}{|c|}{$\begin{array}{c}\text { Comparison between Right and Left Joint } \\
\text { Wilcoxon Test }\end{array}$}} \\
\hline & & & & & & & & & & & & \\
\hline & Mean & \pm SD & Me & Mean & $\pm \mathbf{S D}$ & Me & Mean & $\pm \mathbf{S D}$ & Me & $p$-Value & $\begin{array}{l}\text { Power } \\
(1-\beta)\end{array}$ & $\begin{array}{c}\text { Sample Size } \\
\text { for } 80 \% \text { Test } \\
\text { Power (n) }\end{array}$ \\
\hline Total Integral & 30.48 & 60.83 & 7.75 & 29.08 & 65.53 & 7.20 & 31.88 & 56.37 & 7.85 & 0.699400 & 0.0910029 & 3125 \\
\hline Integral < $300 \mathrm{~Hz}$ & 25.05 & 50.92 & 6.45 & 25.05 & 58.23 & 6.50 & 25.05 & 43.00 & 6.45 & - & - & - \\
\hline Integral > $300 \mathrm{~Hz}$ & 5.43 & 12.47 & 1.00 & 4.04 & 8.21 & 0.80 & 6.81 & 15.59 & 1.25 & 0.033018 * & 0.4019170 & 160 \\
\hline Peak Amplitude & 2.00 & 3.79 & 0.70 & 2.18 & 4.63 & 0.90 & 1.81 & 2.74 & 0.65 & 0.100122 & 0.1538804 & 771 \\
\hline Peak FreQ & 60.13 & 59.62 & 37.00 & 48.74 & 50.95 & 25.00 & 71.52 & 65.74 & 56.00 & 0.003856 * & 0.8294044 & 46 \\
\hline Med. FreQ & 130.01 & 54.10 & 128.00 & 111.88 & 50.80 & 103.00 & 148.14 & 51.59 & 140.00 & 0.000001 * & 0.9992546 & 15 \\
\hline Max Opening & 49.90 & 5.69 & 50.50 & 49.90 & 5.69 & 50.50 & 49.90 & 5.69 & 50.50 & - & - & - \\
\hline
\end{tabular}

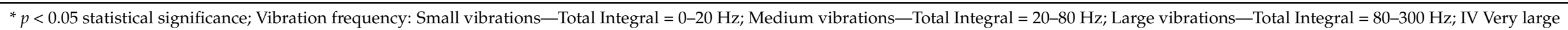

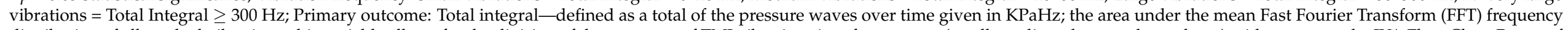

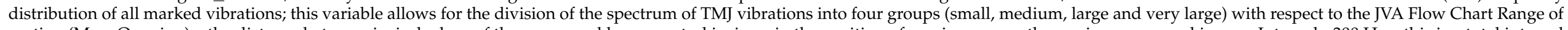

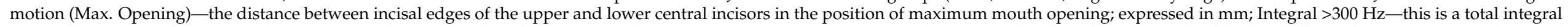

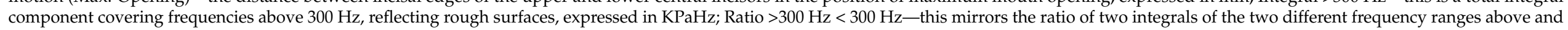

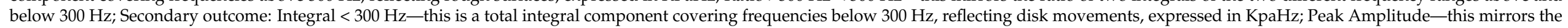

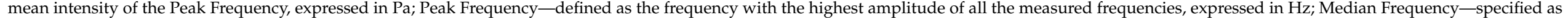
the frequency in the middle of the entire frequency range such that half of the total energy is above and half below, expressed in $\mathrm{Hz}$ [36]. 
Table 4. Parameters of temporomandibular joint vibration analysis in the female group $(n=37)$. The mean values, standard deviation $( \pm \mathrm{SD})$, median $(\mathrm{Me})$ and $p$-value are given.

\begin{tabular}{|c|c|c|c|c|c|c|c|c|c|c|c|c|}
\hline \multirow{3}{*}{$\begin{array}{l}\text { Parameters of Joint } \\
\text { Vibration Analysis }\end{array}$} & \multirow{2}{*}{\multicolumn{3}{|c|}{$\begin{array}{l}\text { All joints in the Entire Study } \\
\text { Group } n=74\end{array}$}} & \multirow{2}{*}{\multicolumn{3}{|c|}{$\begin{array}{l}\text { All Right Joints in the Entire Study } \\
\text { Group } n=37\end{array}$}} & \multirow{2}{*}{\multicolumn{3}{|c|}{$\begin{array}{l}\text { All Left Joints in the Entire Study } \\
\text { Group } n=37\end{array}$}} & \multirow{2}{*}{\multicolumn{3}{|c|}{$\begin{array}{c}\text { Comparison between Right and Left Joint } \\
\text { Wilcoxon Test }\end{array}$}} \\
\hline & & & & & & & & & & & & \\
\hline & Mean & $\pm \mathrm{SD}$ & Me & Mean & $\pm \mathbf{S D}$ & Me & Mean & $\pm \mathbf{S D}$ & Me & $p$-Value & $\begin{array}{l}\text { Power } \\
(1-\beta)\end{array}$ & $\begin{array}{c}\text { Sample Size } \\
\text { for } 80 \% \text { Test } \\
\text { Power (n) }\end{array}$ \\
\hline Total Integral & 32.37 & 66.39 & 8.10 & 32.89 & 75.09 & 8.00 & 31.86 & 57.44 & 8.20 & 0.700460 & 0.0597848 & 28,225 \\
\hline Integral < $300 \mathrm{~Hz}$ & 27.00 & 56.05 & 7.10 & 28.87 & 66.84 & 7.20 & 25.14 & 43.54 & 7.00 & 0.832725 & 0.1011661 & 1609 \\
\hline Integral > $300 \mathrm{~Hz}$ & 5.38 & 13.42 & 1.10 & 4.03 & 9.06 & 0.90 & 6.73 & 16.71 & 1.30 & 0.101808 & 0.2880997 & 188 \\
\hline Peak Amplitude & 2.20 & 4.28 & 0.70 & 2.48 & 5.33 & 0.90 & 1.92 & 2.93 & 0.70 & 0.234751 & 0.1738566 & 443 \\
\hline Peak FreQ & 59.39 & 60.47 & 37.00 & 43.68 & 41.95 & 25.00 & 75.11 & 71.74 & 56.00 & 0.004789 * & 0.9011432 & 28 \\
\hline Med. FreQ & 131.58 & 51.94 & 130.00 & 114.05 & 43.92 & 11500 & 149.11 & 53.95 & 142.00 & 0.000020 * & 0.9931255 & 15 \\
\hline Max Opening & 48.95 & 5.13 & 49.00 & 48.95 & 5.13 & 49.00 & 48.95 & 5.13 & 49.00 & - & - & - \\
\hline
\end{tabular}

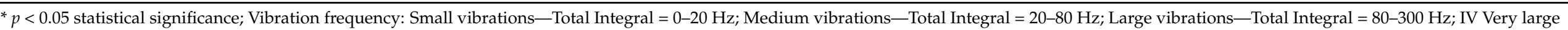

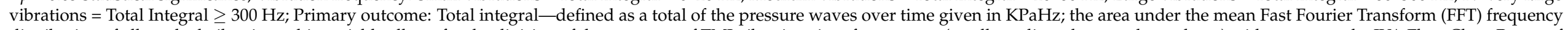

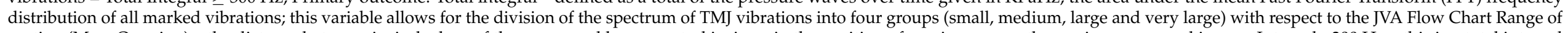

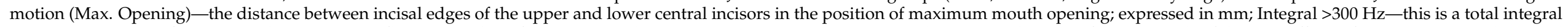

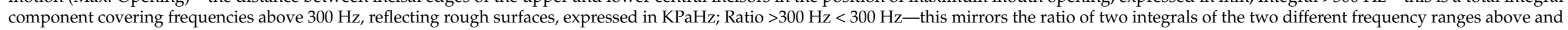

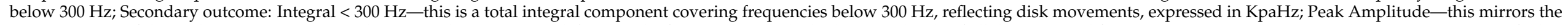

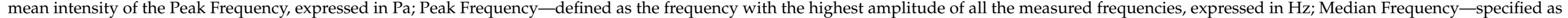
the frequency in the middle of the entire frequency range such that half of the total energy is above and half below, expressed in $\mathrm{Hz}$ [36]. 
Table 5. Parameters of temporomandibular joint vibration analysis in the male group $(n=13)$. The mean values, standard deviation $( \pm \mathrm{SD})$, median $(\mathrm{Me})$ and $p$-value are given.

\begin{tabular}{|c|c|c|c|c|c|c|c|c|c|c|c|c|}
\hline \multirow{3}{*}{$\begin{array}{l}\text { Parameters of Joint } \\
\text { Vibration Analysis }\end{array}$} & \multirow{2}{*}{\multicolumn{3}{|c|}{$\begin{array}{l}\text { All Joints in the Entire Study } \\
\text { Group } n=26\end{array}$}} & \multirow{2}{*}{\multicolumn{3}{|c|}{$\begin{array}{l}\text { All Right Joints in the Entire Study } \\
\text { Group } n=13\end{array}$}} & \multirow{2}{*}{\multicolumn{3}{|c|}{$\begin{array}{l}\text { All Left Joints in the Entire Study } \\
\text { Group } n=13\end{array}$}} & \multirow{2}{*}{\multicolumn{3}{|c|}{$\begin{array}{c}\text { Comparison between Right and Left Joints } \\
\text { Wilcoxon Test } \\
\end{array}$}} \\
\hline & & & & & & & & & & & & \\
\hline & Mean & $\pm \mathbf{S D}$ & Me & Mean & $\pm \mathrm{SD}$ & Me & Mean & $\pm \mathbf{S D}$ & Me & $p$-Value & $\begin{array}{c}\text { Power } \\
(1-\beta)\end{array}$ & $\begin{array}{c}\text { Sample Size } \\
\text { for } 80 \% \text { Test } \\
\text { Power (n) }\end{array}$ \\
\hline Total Integral & 25.09 & 41.72 & 6.65 & 18.24 & 21.14 & 6.40 & 31.94 & 55.47 & 6.90 & 0.944285 & 0.2394969 & 83 \\
\hline Integral $<300 \mathrm{~Hz}$ & 19.49 & 32.46 & 5.80 & 14.16 & 16.46 & 5.70 & 24.82 & 43.16 & 5.90 & 0.506746 & 0.2395178 & 83 \\
\hline Integral > $300 \mathrm{~Hz}$ & 5.57 & 9.51 & 0.75 & 4.07 & 5.40 & 0.70 & 7.06 & 12.42 & 0.90 & 0.139415 & 0.2340410 & 86 \\
\hline$>300 /<300$ Ratio & 0.26 & 0.15 & 0.22 & 0.24 & 0.17 & 0.22 & 0.28 & 0.12 & 0.26 & 0.182339 & 0.2211755 & 95 \\
\hline Peak Amplitude & 1.42 & 1.69 & 0.90 & 1.35 & 1.05 & 1.00 & 1.49 & 2.21 & 0.60 & 0.278708 & 0.0804391 & 1213 \\
\hline Peak FreQ & 62.23 & 58.26 & 35.00 & 63.15 & 70.82 & 29.00 & 61.31 & 45.33 & 41.00 & 0.366986 & 0.0609899 & 7383 \\
\hline Med. FreQ & 125.54 & 60.70 & 111.00 & 105.69 & 68.52 & 91.00 & 145.38 & 46.12 & 138.00 & 0.023130 * & 0.7005520 & 17 \\
\hline Max Opening & 52.62 & 6.53 & 54.00 & 52.62 & 6.53 & 54.00 & 52.62 & 6.53 & 54.00 & - & - & - \\
\hline
\end{tabular}

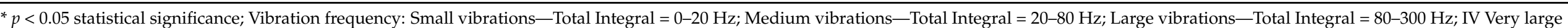

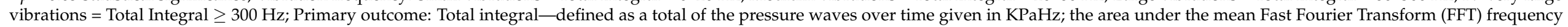

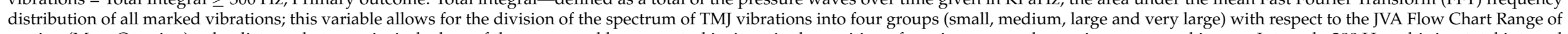

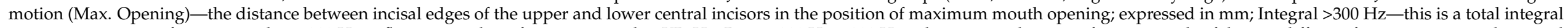

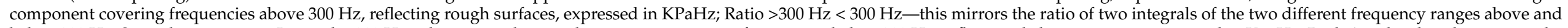

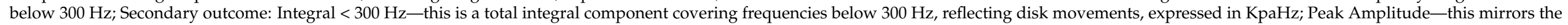

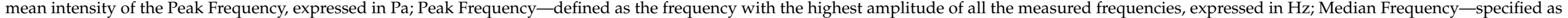
the frequency in the middle of the entire frequency range such that half of the total energy is above and half below, expressed in $\mathrm{Hz}$ [36]. 


\section{Discussion}

The prevalence of temporomandibular disorders shows variation and depends on the population studied and profile of the conducted research. The presented study revealed that many patients had more than one physical diagnosis of TMD (Tables 1 and 2). In 28\% of people, a combination of myofascial pain with referral and bilateral temporomandibular dysfunction was noted (Table 2). Ten percent of the patients revealed a dual diagnosis including myofascial pain with referral and disorder of one of the temporomandibular joints (Table 2).

These observations remain in line with previous findings. John et al. observed that, among 416 females, 266 received one diagnosis, 117 had two diagnoses, 32 subjects had three diagnoses and 1 person obtained four diagnoses. These authors emphasized that such condition is possible because the eight diagnostic categories of Research Diagnostic Criteria for Temporomandibular Disorders (RDC/TMD) are not mutually exclusive [43]. With respect to DC/TMD, Więckiewicz et al. revealed that $55.9 \%$ of 213 individuals demonstrated pain-related TMD including myalgia, myofascial pain, arthralgia and headache attributed to TMD, and $48.8 \%$ reported temporomandibular disorders, mainly disc displacement with reduction $(47.4 \%)$. Furthermore, a total of $73 \%$ of cases had suffered from headaches in the previous 12 months [44].

According to RDC/TMD, Osiewicz et al. revealed that among the Polish patient population, $38 \%$ of the subjects demonstrated the condition of multiple diagnoses, which was defined as a combination of the muscle disorders (I), disc displacement (II) and arthralgia, osteoarthritis and/or osteoarthrosis (III) [45]. A combination of myofascial pain with or without limited opening and disc displacement was observed in $20.5 \%$ of cases. Myofascial pain with or without limited opening and arthralgia was noted in $8.6 \%$ of the patients [45].

A triple diagnosis was observed as a combination of myofascial pain with or without limited opening with osteoarthritis and osteoarthrosis and myofascial pain with or without limited opening with disc displacement and arthralgia. The prevalence of the above mentioned combined conditions was 3.3\% and 1.3\%, respectively. Osiewicz et al. highlighted that in future investigations, a lower incidence of myofascial pain could be expected [45]. The reason for that is the fact that currently used DC/TMD protocol are much more restrictive than previously used RDC/TMD where it concerns the criteria for the diagnosis of myofascial pain [45].

With respect to DC/TMD and selected Northern Jordanian population aged between 18 and 78 years, the frequency of myofascial pain with referral amounted to $2.2 \%$ [28]. A combination of myofascial pain with referral and arthralgia was reported at a similar level in $2.2 \%$ of cases. Myofascial pain without a referral pattern and arthralgia was noted in $0.8 \%$ of the patients. Local myalgia and arthralgia was reported in $0.3 \%$ of the subjects [28]. According to RDC/TMD, Rauch et al. stated that, among the German population, 34.4\% of people received no TMD diagnosis. The next $65.6 \%$ suffered from TMD [46]. Of those patients $55.5 \%$ obtained single, and $44.5 \%$ received multiple diagnoses [46].

According to the diagnostic criteria of the American Academy of Orofacial Pain (AAOP), Machado et al. revealed that only $6.7 \%$ of the patients had only one diagnosis [47]. In $93.3 \%$ of the cases, patients had at least one more problem diagnosed along with the main diagnosis. In $13.7 \%$ of people, five different conditions were simultaneously recognized. As the main diagnosis, masticatory myofascial pain was reported in $10.4 \%$ of the patients [47]. As the complex of the main and additional diagnoses, masticatory myofascial pain was demonstrated in $24.1 \%$ of people.

The presence of multiple diagnoses broadens the area for treatment possibilities. In addition to causal treatment aimed at treating multi-dimensional myofascial pain with referral, it is necessary to take steps to alleviate intra-articular dysfunction. The most accepted model considers directed and self-directed biopsychosocial profile modulation and symptomatic treatment [30]. 
The first solution includes a proposal of cognitive behavioural therapy, biofeedback, sleep hygiene measures and relaxation techniques [30]. Symptomatic treatment involves occlusal splints, pharmacological therapy, trigger point therapy, soft tissue mobilization, occlusal equilibration, prosthodontic reconstruction, acupuncture, botulinum toxin, transcutaneous electrical neuromuscular stimulation (TENS) and/or contingent electrical stimulation $[30,38]$. The new challenge in TMD management entails the creation of a relevant set of biomarkers for temporomandibular disorders-quantitative sensory measures and a genomic or molecular profile [1].

In presented study, only $33 \%(n=33)$ of all temporomandibular joints $(n=100)$ were affected by the pathology (Table 1). However, the presence of even these structural and/or functional changes may indicate profound progression in temporomandibular dysfunction. As previously mentioned, the prevalence of muscular disorder tend to be more common than those that are intracapsular joint-related [26-28] and musculoskeletal dysfunction appear to be the primary source of TMD development [29].

Machado et al. highlighted that patients with chronic muscle dysfunction exposed to long-term parafunctional habits-especially clenching - revealed secondary organic changes within TMJ [47]. In turn, in the case of primary TMJ pathology, subsequent muscle symptoms could appear as a consequence of the protective splinting of the jaws. Through deep pain and by creating cyclical muscle pain, this last mechanism may lead to the incidence of cumulative trauma [47]. It should be highlighted that triggers for myofascial pain include emotional stress, tension, fatigue, overloads, nutritional deficiencies, infections, unhealthy behavior and poor ergonomics [38].

It is also well known that changes in head posture influence a response within the masticatory system including the biomechanical behavior of TMJ and its associated structures [48,49]. Head position affects the resting position of the mandible, modifies muscular activity and alters the internal arrangement of the TMJ. A close link exists between head and cervical posture improvement and relief of the symptoms of temporomandibular joint [48].

The above mentioned feedback could be reflected by the anatomophysiological components of $\mathrm{C} 0-\mathrm{C} 2$ complex (Occiput-Axis) and convergence phenomenon within cervical and trigeminal afferents in the trigeminocervical nucleus [5,50]. In summary, in temporomandibular disorder, researchers should pay attention to the cervical spine and associated head position, the phenomenon of convergence and the central sensitization of pain [51-53].

In the presented study, 31 patients demonstrated a healthy condition of both temporomandibular joints (Table 2). Bearing in mind the main diagnosis-myofascial pain with referral-this may support the suggestion that muscle dysfunction precedes joint disorders and that muscle dysfunction appears as the primary cause of TMD development. This suggestion seems to be in line with Wolff's law and bone functional adaptation as well as the biotensegrity model of TMJ [33,54]. To summarize, "form follows function" [22]. On the other hand, early detection of muscle dysfunction enables the implementation of appropriate primary, secondary or tertiary prevention $[55,56]$.

With respect to JVA, the estimation of the Total Integral enables division of the spectrum of TMJ vibrations into four groups of intensity-small (0-20 KPaHZ), medium (20-80 KPaHZ), large (80-300 KPaHZ) and very large vibrations (>300 KPaHZ) (Tables 3-5) [36]. Very large vibrations may indicate the acute phase of disc displacement with reduction (stage Piper $4 \mathrm{~A})$. When the acute phase becomes more chronic, the Total Integral decreases [36]. Radke et al. emphasized that, in the case of acute or the well adapted stage of Piper 4B, a low level of Total Integral could be observed. During adaptation of the Piper $4 \mathrm{~B}$ condition, medium results were reported [36].

The results of the JVA correspond with other previous findings. Kondrat et al. showed that, in a group of healthy people $(n=186)$ with an average age of 19 years, the Total Integral amounted to $39.02 \pm 63.97 \mathrm{KPaHz}$ among females $(\mathrm{Me}=16.35 \mathrm{KPaHz})$ and to $39.02 \pm 67.92 \mathrm{KPaHz}$ in males $(\mathrm{Me}=19.45 \mathrm{KPaHz})$ [41]. In our study, this variable scored $32.37 \pm 66.39 \mathrm{KPaHz}(\mathrm{Me}=8.10 \mathrm{KPaHz})$ in females and $25.09 \pm 41.72 \mathrm{KPaHz}$ 
$(\mathrm{Me}=6.65 \mathrm{KPaHz})$ in males (Tables 4 and 5). Slight differences between both study results are likely conditioned by the different sample sizes and prevalence of people with healthy joints within the entire study group.

Kondrat et al. revealed that Integral $<300 \mathrm{~Hz}$ amounted to $31.33 \pm 54.83 \mathrm{KPaHz}$ $(\mathrm{Me}=14.15 \mathrm{KPaHz})$ in females and $35.86 \pm 63.41 \mathrm{KPaHz}(\mathrm{Me}=18.05 \mathrm{KPaHz})$ in males [41]. In our study, this outcome reached $27.00 \pm 56.05 \mathrm{KpaHz}(\mathrm{Me}=7.10 \mathrm{KpaHz})$ in females and $19.49 \pm 32.46(\mathrm{Me}=5.80 \mathrm{KpaHz})$ in males (Tables 4 and 5$)$. Integral $<300 \mathrm{~Hz}$ is associated with incorrect disc movements [36]. Values of this outcome close to the Total Integral prove that the reported vibration results from irregular disc motion, not from any other degenerative changes. On the other hand, as the main vibration, the Integral $>300 \mathrm{~Hz}$ reflects relative roughness of the sliding surfaces within TMJ and is considered only in the case of small and medium amplitude vibrations [36].

Kondrat et al. reported that the Ratio $>300 /<300 \mathrm{~Hz}$ was $0.15 \pm 0.15$ in females and $0.14 \pm 0.14$ in males [41]. In our study, this outcome amounted to $0.23 \pm 0.17$ in females and $0.26 \pm 0.15$ in males (Tables 4 and 5). Evaluation of the Ratio $>300 /<300 \mathrm{~Hz}$ permits avoidance of overestimating any degenerative changes with large or very large vibrations. This outcome is not considered in the case of small vibrations. The reason is the potential background of electrical noises that represent artifacts [36].

The Peak Amplitude is taken into account in the case of hearing noise within TMJs that are reported by the patients. Values below 6.0 (Newtons $/$ meter $^{2} ; \mathrm{Pa}$ ) appear to be a crepitus. Results above 6.0 Pa are typical in normal hearing [36].

The next outcome described as a Peak Frequency indicates long-term chronicity. Longlasting temporomandibular pathology means lower values of Peak Frequency. Similar to the Peak Frequency, the Median Frequency suggests chronicity of TMD. In the case of a discrepancy between values of the Median Frequency and the Peak Frequency and by the dominance of the Median Frequency, there exists some possibility of active degenerative condition occurrence [36].

Despite the fact that there was no sided domination (left/right) in the prevalence of temporomandibular disorder (Table 1), all statistically significant differences reported with respect to JVA suggest profound progression of dysfunction within the left TMJ compared to the right one (Tables 3-5). This lateralization could reflect descending or ascending cranio-mandibular, homo- or heterolateral dysfunction [57].

\section{Strengths and Limitations of the Study}

This is probably the first study on joint vibration analysis performed in patients with temporomandibular joint disorders - myofascial pain with referral - who were diagnosed with respect to DC/TMD. Applied protocol allowed for the selection of a homogenous group of patients with regard to the strictly defined research criteria.

The main advantage is the fact that JVA is a reliable screening tool with a specificity of $98 \%$ [36]. As opposed to palpation and auscultation with stethoscope JVA enables timely, quantitative estimation of dynamic function of the temporomandibular joints and evaluation of the degree of temporomandibular sounds [36]. It supports clinical diagnosis and indicates the need to perform CBCT or MRI [36].

The main limitation of the study was the small sample size and the possibility of bias regarding selection, measurement and confounding factors. Thus, the presented data should be treated with caution. Selection bias usually arises from the general study design or/and data collection. The current research favors details from patients with temporomandibular joint disorder including myofascial pain with referral, who were additionally selected with respect to the strictly defined inclusion and exclusion criteria. In an unbiased sample, differences observed between the cases of units from a population and those from the entire population they represent, should originate only by chance. Otherwise, it would indicate selection bias.

Another issue is measurement bias. As mentioned before, BioJVA is a reliable device with very high sensitivity. However, proper registration requires repeatable, individually 
declared mouth opening. Sometimes, in the case of patients with acute pain this may be difficult to achieve and may result in omission of important vibrations. Also in the case of inflammatory exudate that separates the anatomical structures in the temporomandibular joint, the perception of vibrations may be reduced. Head position and posture during registration also could play a significant role.

Confounding bias refers to an inappropriate association made between an outcome and a factor. It suggests some relationship that does not exist or masks a true relationship. Due to the specificity of the presented study group and the tested differences, the following confounding factors should be considered: sample size, age, gender, one sided or bilateral chewing, individual morphology of temporomandibular joints, posture disorders and lateralization.

\section{Conclusions}

The relatively high prevalence of multiple diagnoses proved the overlapping nature of muscle and intraarticular disorders. Twenty eight percent of the subjects suffered from a combination of myofascial pain with referral and bilateral temporomandibular dysfunction. In $62 \%$ of the patients, a lack of intraarticular disorders was reported. The suggestion that there exists sided domination in the occurrence of temporomandibular disorders has not been confirmed. Due to the small sample size, such differences cannot be excluded. With regard to other limitations of the study, further research is needed.

Author Contributions: Conceptualization: J.K. and K.D.S.; data curation: J.K.; formal analysis: J.K.; funding acquisition: J.K.; investigation: J.K. and K.D.S.; methodology: J.K. and K.D.S.; project administration: J.K.; resources: J.K. and K.D.S.; software: J.K.; supervision: M.G.; validation: J.K. and K.D.S.; visualization: J.K.; writing-original draft: J.K.; writing-review and editing: J.K.; K.D.S. and M.G. All authors have read and agreed to the published version of the manuscript.

Funding: This study was supported by the Medical University of Bialystok, Poland (grant number: N/ST/MN/16/001/1113).

Institutional Review Board Statement: The study was conducted according to the guidelines of the Declaration of Helsinki and approved by the Bioethics Committee of the Medical University of Bialystok, Poland (permit number: R-I-002/322/2016).

Informed Consent Statement: Informed consent was obtained from all subjects involved in the study.

Data Availability Statement: The article contains complete data used to support the findings of this study.

Conflicts of Interest: The authors declare no conflict of interest.

\section{References}

1. Schiffman, E.; Ohrbach, R.; Truelove, E.; Look, J.; Anderson, G.; Goulet, J.-P.; List, T.; Svensson, P. Diagnostic criteria for temporomandibular disorders (DC/TMD) for clinical and research applications: Recommendations of the International RDC/TMD Consortium Network and Orofacial Pain Special Interest Group. J. Oral Facial Pain Headache 2014, 28, 6-27. [CrossRef]

2. Perrotta, S.; Bucci, R.; Simeon, V.; Martina, S.; Michelotti, A.; Valletta, R. Prevalence of malocclusion, oral parafunctions and temporomandibular disorder-pain in Italian schoolchildren: An epidemiological study. J. Oral Rehabil. 2019, 46, 611-616. [CrossRef] [PubMed]

3. Macfarlane, T.; Gray, R.; Kincey, J.; Worthington, H. Factors associated with the temporomandibular disorder, pain dysfunction syndrome (PDS): Manchester case-control study. Oral Dis. 2001, 7, 321-330. [CrossRef] [PubMed]

4. Oliveira, C.B.; Lima, J.A.S.; Silva, P.L.P.; Forte, F.D.S.; Bonan, P.R.F.; Batista, A.U.D. Temporomandibular disorders and oral habits in high-school adolescents: A public health issue? RGO Rev. Gaúch. Odontol. 2016, 64, 08-16. [CrossRef]

5. Kuć, J.; Szarejko, K.D.; Sierpinska, T. Evaluation of Orofacial and General Pain Location in Patients With Temporomandibular Joint Disorder-Myofascial Pain With Referral. Front. Neurol. 2019, 10, 546. [CrossRef]

6. Chung, J.; Lobbezoo, F.; van Selms, M.K.; Chattrattrai, T.; Aarab, G.; Mitrirattanakul, S. Physical, psychological and sociodemographic predictors related to patients' self-belief of their temporomandibular disorders' aetiology. J. Oral Rehabil. 2021, 48, 109-123. [CrossRef] 
7. Sójka, A.; Stelcer, B.; Roy, M.; Mojs, E.; Pryliński, M. Is there a relationship between psychological factors and TMD? Brain Behav. 2019, 9, e01360. [CrossRef]

8. Umniyati, H. The prevalence of Temporomandibular DisorderJoint (TMD) and its severity among YARSI University Employees. J. Dentomaxillofac. Sci. 2020, 5, 82-85. [CrossRef]

9. Ram, H.; Shah, D. Prevalence of sign and symptoms of TMD among the patients attending Siddhpur dental college and hospital of Gujarat. Int. J. Appl. Dent. Sci. 2020, 6, 671-675. [CrossRef]

10. Li, D.T.S.; Leung, Y.Y. Temporomandibular Disorders: Current Concepts and Controversies in Diagnosis and Management. Diagnostics 2021, 11, 459. [CrossRef]

11. Schiffman, E.; Ohrbach, R. Executive summary of the Diagnostic Criteria for Temporomandibular Disorders for clinical and research applications. J. Am. Dent. Assoc. 2016, 147, 438-445. [CrossRef] [PubMed]

12. Dworkin, S.F. Research diagnostic criteria for temporomandibular disorders: Review, criteria, examinations and specifications, critique. J. Craniomandib. Disord. 1992, 6, 301-355.

13. Whyte, A.; Phoon Nguyen, A.; Boeddinghaus, R.; Balasubramaniam, R. Imaging of temporomandibular disorder and its mimics. J. Med. Imaging Radiat. Oncol. 2021, 65, 70-78. [CrossRef]

14. Marpaung, C.; Lobbezoo, F.; van Selms, M.K. Temporomandibular disorders among Dutch adolescents: Prevalence and biological, psychological, and social risk indicators. Pain Res. Manag. 2018, 2018, 5053709. [CrossRef] [PubMed]

15. Nomura, K.; Vitti, M.; Oliveira, A.S.d.; Chaves, T.C.; Semprini, M.; Siéssere, S.; Hallak, J.E.C.; Regalo, S.C.H. Use of the Fonseca's questionnaire to assess the prevalence and severity of temporomandibular disorders in Brazilian dental undergraduates. Braz. Dent. J. 2007, 18, 163-167. [CrossRef] [PubMed]

16. Kapos, F.P.; Exposto, F.G.; Oyarzo, J.F.; Durham, J. Temporomandibular disorders: A review of current concepts in aetiology, diagnosis and management. Oral Surg. 2020, 13, 321-334. [CrossRef]

17. Xu, L.; Cai, B.; Lu, S.; Fan, S.; Dai, K. The Impact of Education and Physical Therapy on Oral Behaviour in Patients with Temporomandibular Disorder: A Preliminary Study. BioMed Res. Int. 2021, 2021, 6666680. [PubMed]

18. Stocka, A.; Sierpinska, T.; Kuc, J.; Golebiewska, M. Relationship between depression and masticatory muscles function in a group of adolescents. CRANIO® 2018, 36, 390-395. [CrossRef]

19. Kuć, J.; Szarejko, K.D.; Aleksandrowicz, K.; Gołębiewska, M. The role of soft tissue mobilization in reducing orofacial and general complaints in a patient with Kimmerle anomaly and temporomandibular joint disorder: A case report. CRANIO® 2021, 39, 74-87. [CrossRef]

20. Skármeta, N.P.; Pesce, M.C.; Saldivia, J.; Espinoza Mellado, P.; Montini, F.; Sotomayor, C. Changes in understanding of painful temporomandibular disorders: The history of a transformation. Quintessence Int. 2019, 50, 662-669. [PubMed]

21. Manfredini, D.; Lombardo, L.; Siciliani, G. Temporomandibular disorders and dental occlusion. A systematic review of association studies: End of an era? J. Oral Rehabil. 2017, 44, 908-923. [CrossRef]

22. Sierpinska, T.; Jacunski, P.; Kuc, J.; Golebiewska, M.; Wieczorek, A.; Majewski, S. Effect of the dental arches morphology on the masticatory muscles activities in normal occlusion young adults. CRANIO® 2015, 33, 134-141. [CrossRef] [PubMed]

23. Sierpinska, T.; Kuc, J.; Golebiewska, M. Morphological and functional parameters in patients with tooth wear before and after treatment. Open Dent. J. 2013, 7, 55-61. [CrossRef]

24. Sierpinska, T.; Kropiwnicka, A.; Kuc, J.; Jacunski, P.; Gołębiewska, M. The influence of occlusal morphology on occlusion time. CRANIO® 2017, 35, 101-109. [CrossRef] [PubMed]

25. Sierpinska, T.; Kuc, J.; Golebiewska, M. Assessment of masticatory muscle activity and occlusion time in patients with advanced tooth wear. Arch. Oral Biol. 2015, 60, 1346-1355. [CrossRef] [PubMed]

26. Elhayes, K.; Hassanien, N. Efficacy of soft occlusal splint therapy in management of temporomandibular disorders. J. Am. Sci. 2012, 8, 1-8.

27. Devi, J.; Verma, M.; Gupta, R. Assessment of treatment response to splint therapy and evaluation of TMJ function using joint vibration analysis in patients exhibiting TMJ disc displacement with reduction: A clinical study. Indian J. Dent. Res. 2017, 28, 33-43. [CrossRef]

28. Alrashdan, M.S.; Nuseir, A.; AL-Omiri, M.K. Prevalence and correlations of temporomandibular disorders in Northern Jordan using diagnostic criteria axis I. J. Investig. Clin. Dent. 2019, 10, e12390. [CrossRef]

29. Lomas, J. Temporomandibular dysfunction. Aust. J. Gen. Pract. 2018, 47, 212-215. [CrossRef] [PubMed]

30. Golanska, P.; Saczuk, K.; Domarecka, M.; Kuć, J.; Lukomska-Szymanska, M. Temporomandibular Myofascial Pain Syndrome -Aetiology and Biopsychosocial Modulation. A Narrative Review. Int. J. Environ. Res. Public Health 2021, 18, 7807. [CrossRef]

31. Liu, F.; Steinkeler, A. Epidemiology, diagnosis, and treatment of temporomandibular disorders. Dent. Clin. 2013, 57, 465-479. [CrossRef]

32. Peck, C.C.; Goulet, J.P.; Lobbezoo, F.; Schiffman, E.L.; Alstergren, P.; Anderson, G.C.; de Leeuw, R.; Jensen, R.; Michelotti, A.; Ohrbach, R. Expanding the taxonomy of the diagnostic criteria for temporomandibular disorders. J. Oral Rehabil. 2014, 41, 2-23. [CrossRef]

33. Kuć, J.; Szarejko, K.D.; Gołębiewska, M. Comparative Evaluation of Occlusion before and after Soft Tissue Mobilization in Patients with Temporomandibular Disorder-Myofascial Pain with Referral. Int. J. Environ. Res. Public Health 2021, 18, 6568. [CrossRef]

34. Kmeid, E.; Nacouzi, M.; Hallit, S.; Rohayem, Z. Prevalence of temporomandibular joint disorder in the Lebanese population, and its association with depression, anxiety, and stress. Head Face Med. 2020, 16, 19. [CrossRef] 
35. Fernández-de-Las-Peñas, C.; Svensson, P. Myofascial temporomandibular disorder. Curr. Rheumatol. Rev. 2016, 12, 40-54. [CrossRef] [PubMed]

36. Radke, J.; Velasco, G.R. Joint Vibration Analysis (JVA) Bridges the Gap between Clinical Procedures and Sophisticated TMJ Imaging. Adv. Dent. Tech. 2020, 3, 17315.

37. Ohrbach, R.; Gonzalez, Y.; List, T.; Michelotti, A.; Schiffman, E. Diagnostic Criteria for Temporomandibular Disorders (DC/TMD) Clinical Examination Protocol. Available online: www.rdc-tmdinternational.org (accessed on 2 June 2013).

38. Kuć, J.; Szarejko, K.D.; Gołębiewska, M. Evaluation of Soft Tissue Mobilization in Patients with Temporomandibular DisorderMyofascial Pain with Referral. Int. J. Environ. Res. Public Health 2020, 17, 9576. [CrossRef] [PubMed]

39. Kuć, J.; Szarejko, K.D.; Gołębiewska, M. Smiling, Yawning, Jaw Functional Limitations and Oral Behaviors With Respect to General Health Status in Patients With Temporomandibular Disorder-Myofascial Pain With Referral. Front. Neurol. 2021, 12, 646293. [CrossRef] [PubMed]

40. Droter, J.R. An orthopaedic approach to the diagnosis and treatment of disorders of the temporomandibular joint. Dent. Today. 2005, 24, 82, 84-88.

41. Kondrat, W.; Sierpińska, T.; Radke, J. Assessment of the temporomandibular joint function in young adults without complaints from the masticatory system. Int. J. Med. Sci. 2018, 15, 161-169. [CrossRef] [PubMed]

42. von Piekartz, H. Physical examination of dysfunctions in the craniomandibular region. In Craniofacial Pain: Neuromusculoskeletal Assessment, Treatment and Management; von Piekartz, H., Ed.; Butterworth-Heinemann: Edinburgh, UK, 2007 ; pp. 159-214.

43. John, M.T.; Reißmann, D.R.; Schierz, O.; Wassell, R.W. Oral Health-Related Quality of Life in Patients with Temporomandibular Disorders. J. Orofac. Pain 2007, 21, 46-54.

44. Wieckiewicz, M.; Grychowska, N.; Nahajowski, M.; Hnitecka, S.; Kempiak, K.; Charemska, K.; Balicz, A.; Chirkowska, A.; Zietek, M.; Winocur, E. Prevalence and Overlaps of Headaches and Pain-Related Temporomandibular Disorders Among the Polish Urban Population. J. Orofac. Pain Headache 2020, 34, 31-49. [CrossRef]

45. Osiewicz, M.A.; Lobbezoo, F.; Loster, B.W.; Loster, J.E.; Manfredini, D. Frequency of temporomandibular disorders diagnoses based on RDC/TMD in a Polish patient population. Cranio® 2018, 36, 304-310. [CrossRef]

46. Rauch, A.; Hahnel, S.; Kloss-Brandstätter, A.; Schierz, O. Patients referred to a German TMD-specialized consultation hour-A retrospective on patients without a diagnosis according to RDC/TMD decision trees. Clin. Oral Investig. 2021, 25, 5641-5647. [CrossRef]

47. Pimenta e Silva Machado, L.; de Góis Nery, C.; Rodrigues Leles, C.; Batista de Macedo Nery, M.; Okeson, J.P. The prevalence of clinical diagnostic groups in patients with temporomandibular disorders. CRANIO® 2009, 27, 194-199. [CrossRef] [PubMed]

48. Olivo, S.A.; Bravo, J.; Magee, D.J.; Thie, N.M.; Major, P.W.; Flores-Mir, C. The association between head and cervical posture and temporomandibular disorders: A systematic review. J. Orofac. Pain 2006, 20, 9-23. [PubMed]

49. Olivo, S.A.; Fuentes, J.; Major, P.; Warren, S.; Thie, N.; Magee, D. The association between neck disability and jaw disability. J. Oral Rehabil. 2010, 37, 670-679. [CrossRef]

50. Bogduk, N.; Govind, J. Cervicogenic headache: An assessment of the evidence on clinical diagnosis, invasive tests, and treatment. Lancet Neurol. 2009, 8, 959-968. [CrossRef]

51. Campi, L.; Jordani, P.; Tenan, H.; Camparis, C.; Gonçalves, D. Painful temporomandibular disorders and central sensitization: Implications for management-A pilot study. Int. J. Oral Maxillofac. Surg. 2017, 46, 104-110. [CrossRef]

52. Monaco, A.; Cattaneo, R.; Marci, M.C.; Pietropaoli, D.; Ortu, E. Central Sensitization-Based Classification for Temporomandibular Disorders: A Pathogenetic Hypothesis. Pain Res. Manag. 2017, 2017, 5957076. [CrossRef]

53. La Touche, R.; Paris-Alemany, A.; Hidalgo-Pérez, A.; López-de-Uralde-Villanueva, I.; Angulo-Diaz-Parreño, S.; Muñoz-García, D. Evidence for central sensitization in patients with temporomandibular disorders: A systematic review and meta-analysis of observational studies. Pain Pract. 2018, 18, 388-409. [CrossRef] [PubMed]

54. Ruff, C.; Holt, B.; Trinkaus, E. Who's afraid of the big bad Wolff?:"Wolff's law” and bone functional adaptation. Am. J. Phys. Anthropol. 2006, 129, 484-498. [CrossRef] [PubMed]

55. Booth, F.W.; Roberts, C.K.; Laye, M.J. Lack of exercise is a major cause of chronic diseases. Compr. Physiol. 2012, 2, 1143-1211. [PubMed]

56. Kuć, J.; Żendzian-Piotrowska, M. Evaluation of the Cervical Physiotherapeutic Treatment Needs, Work Ergonomics, and Necessity for Physical Activity Among Students of Dentistry at a Medical University. A Pilot Study. Front. Psychol. 2020, 11, 2798. [CrossRef] [PubMed]

57. Dupas, P.H. Nouvelle Approche du Dysfonctionnement Cranio-Mandibulaire: Du diagnostic à la Gouttière; Wolters Kluwer: Paris, France, 2005; pp. 97-124. 